Cần có biện pháp hỗ trợ tâm lý người bệnh ngay từ sớm để làm giảm tỷ lệ trầm cảm của họ. Uu tiên cho nhóm đối tượng thu nhập thấp, không ổn định, đang điều trị bệnh khác, không có người hố trợ.

\section{TÀI LIÊU THAM KHẢO}

1. BMj Publishing Group (2018), Tổng quan về HIV, BMJ Best Practice.

2. Maria Giulia Nanni và các công sự (2015), "Depression in HIV infected patients: a review", Current psychiatry reports. 17(1), pp. 530.

3. Pham Đình Quyêt, võ Thị Duyên, Huỳnh Ngọc Vân Anh (2018), "Trầm cảm và các yếu tố liên quan ở ngưới nhiếm HIV/AIDS đang điêuu trị ARV", Tap chí Y học thành phố Hồ Chí Minh. 22(1), pp. 285-292.

4. Đăng Thị Minh Trang (2018), Rối loan trầm cảm trên người sống chung với HIV/AIDS đang điều trị ARV tại phòng khám ngoại trú Thuân An, Bình Dương, Hội nghị khoa học kỹ thuật lẩn thứ 35, Đai hoc $Y$ dược thành phố Hồ Chí Minh.

5. Huỳnh Ngọc Vần Anh (2017), Trầm cảm và các yêu tố liên quan ở những người nhiễm HIV điều trì ARV, Hội nghị khoa học kỹ thuật lần 34, Đại học Y Dược thành phố Hồ Chí Minh.

6. Bhatia. MS and Sahil Munjal (2014), "Prevalence of depression in people living with HIV/AIDS undergoing ART and factors associated with it", Journal of clinical and diagnostic research: JCDR. 8(10), pp. WC01

7. S. Algoodkar et al. (2017), "Prevalence and Factors associated with Depression among Clinically Stable People Living with HIV/AIDS on Antiretrovira Therapy", Indian J Psychol Med. 39(6), pp. 789-793

8. Tesfaw. G et al. (2016), "Prevalence and correlates of depression and anxiety among patients with HIV on-follow up at Alert Hospital, Addis Ababa, Ethiopia", BMC Psychiatry. 16(1), pp. 368.

\title{
HIỆU QUẢ CAN THIỆP CẢI THIÊ̂N TUÂN THỦ ĐIỀU TRI, ĐẠT HUYẾT ÁP MỤC TIÊU Ở BÊNNH NHÂN TĂNG HUYẾT ÁP TAI TRAM Y TẾ PHƯỜNG, QUậN THỦ ĐỨC, THÀNH PHỐ HỒ CHÍ MINH
}

\author{
Trần Quốc Cường*, Lê Văn Bào**, Nguyễn Anh Tuấn**
}

\section{TÓM TẮT}

Muc tiêu: Đánh giá hiêu quả can thiêp cải thiên tuân thủ điêu trị, đạt huyết áp mục tiêu ở bệnh nhẩn tăng huyết áp tại trạm y tế phường Linh Xuân, quận Thủ Đức, thành phố Hồ Chí Minh (2019 - 2020). Phương pháp: Mô tả cắt ngang; phỏng vấn đối tượng, khám lâm sàng, đo huyết áp; can thiệp điều trị THA, giáo duc, tư vấn về tuân thủ chế độ điều tri cho BN THA và đánh giá hiệu quả can thiệp. Kết quả: Tỷ lê tuân thủ chế đô̂ điêu tri như: uống thuốc, tái khám định kỳ, kiểm tra HA thường xuyên, chế độ ăn, uống, lối sônng (giảm mặn, tăng rau/củ/quả, giảm chất béo, giảm rượu/bia, ngưng hút thuốc, tập thể dục thường xuyên) đươợc cải thiện rõ rêt. Sự khác biệt về tỷ lệ tuân thủ các chế độ ở cả bốn thời điểm T3, T6, T12 và T18 so với T0 đều có ý nghĩa thống kê $(p<0,05)$. Tăng tỷ lệ BN đạt HA mục tiêu sau can thiệp 18 tháng (T18) lển 94,5\% (nữ: 98,1\% cao hơn nam: $90,0 \%$; nhóm BN <50 tuổi: 97,0\% cao hơn nhóm 50-59 tuổi: 96,6\% và nhóm 60-69 tuổi: 92,2\%). Kết luận: Tỷ lệ $B N$ tuân thủ các chế độ uống thuốc, tái khám đinh kỳ, kiểm tra HA thường xuyên, chế độ ăn, uống, lối sống được cải thiện rõ rệt. Tăng tỷ lẹ đạt HA mục tiêu sau can thiệp

*Trung tâm y tế dự phòng (CDC) Thành phố Thủ Đức, TP. Hồ Chí Minh

**Hoc viên Quân y

Chịu trách nhiệm chính: Trần Quốc Cường

Email: quoccuong.mph@gmail.com

Ngày nhận bài: 2.8 .2021

Ngày phản biên khoa hoc: 27.9.2021

Ngày duyệt bài: 4.10 .2021
18 tháng lên $94,5 \%$

Tư khóa: Can thiệp, tuân thủ điêu trị, huyết áp mục tiêu, trạm y tế.

\section{SUMMARY}

\section{EFFECTS OF INTERVENTION TO IMPROVE}

TREATMENT COMPLIANCE, ACHIEVE TARGET BLOOD PRESSURE IN HYPERTENSIVE PATIENTS AT HEALTH STATION OF WARD, THU DUC DISTRICT, HO CHI MINH CITY

Objective Evaluating the effectiveness of interventions to improve treatment adherence, achieve target blood pressure in hypertensive patients at the medical station of Linh Xuan ward, Thu Duc district, Ho Chi Minh city (2019 - 2020). Methods: Horizontal cut representation; subject interview, clinical examination, blood pressure measurement; hypertensive interventions, education, counseling on adherence to treatment regimens for hypertensive patients and assessment of intervention effectiveness. Results: The rate of adherence to treatment regimens such as: taking medications, periodic followup visits, regular blood pressure checks, diet, drinking, lifestyle (reducing salt, increasing vegetables/ vegetables/fruits, reducing fat, reducing alcohol) /beer, smoking cessation, regular exercise) improved markedly. The difference in the rate of adherence to the regimens at all four time points T3, T6, T12 and T18 compared with T0 was statistically significant $(p<0.05)$. Increase the rate of reaching target blood pressure after 18 months of intervention (T18) to $94.5 \%$ (female: $98.1 \%$ higher than male: $90.0 \%$; patient group $<50$ years old: $97.0 \%$ higher than the 
group: $97.0 \%$ higher than the group of patients $<50$ years old: $97.0 \%$ ). $50-59$ years old: $96.6 \%$ and $60-69$ years old: $92.2 \%)$. Coclusion: The rate of adherence to taking medications, periodic follow-up visits, regular blood pressure checks, and adherence to diet, drinking, and lifestyle were markedly improved. Increase the rate of achieving target BP after intervention 18 months (T18) to $94.5 \%$.

Keywords; Intervention, treatment adherence, target blood pressure, health station.

\section{I. ĐẶT VẤN ĐỀ}

Tăng huyết áp (THA) là bệnh lý tim mạch phổ biến và nguy hiểm, bệnh đang có xu hướng gia tăng trên toàn thế giới và được mệnh danh là "kẻ giết người thầm lặng". Theo ước tính của Tổ chức Y tế thế giới, tỷ lệ THA trên thế giới năm 2000 là 26,4\% tương đương 972 triệu người và dự kiến đến năm 2025 tỷ lệ này sẽ tăng lên 29,2\% (khoảng 1,56 tỷ người). Tại Việt Nam, theo báo cáo của Hội Tim Mạch, tính đển tháng $5 / 2016$ tỷ lệ THA là 47,3\%, trong đó chỉ có $31,3 \%$ THA kiểm soát được [1]. THA là bệnh mạn tính, đòi hỏi $B N$ phải kiên trì điều trị và tuân thủ chế độ điều trị. Một trong nhưng mục tiêu quan trọng của điều trị THA là BN phải sớm đạt được HA mục tiêu $(<140 / 90 \mathrm{mmHg})$. Để đạt được $\mathrm{HA}$ mục tiêu, BN phải tuân thủ chễ độ điều trị, nếu không tuân thủ chế độ điều trị BN có thể mắc nhiều biến chứng, ảnh hưởng đến tính mạng và trở thành gánh nặng cho gia đình và xã hội. BN THA không được kiểm soát thì nguy cơ mắc bệnh động mạch vành tăng gấp 3 lần, mắc suy tim gấp 6 lần và đột quy gấp 7 lần [2]. Vì thế sự tuân thủ trong điêu trị THA của BN là vô cùng quan trọng. Đây chính là yếu tố quyết định sự thành công trong điêu trị. Trên thế giới, nghiên cứu của Morisky năm 2008 chỉ có $15,9 \%$ BN tuân thủ dùng thuốc trong điều trị [3]. Saleem tại Pakistan năm 2011, có $61,3 \%$ BN có hiểu biết trung bình về THA và không có $B N$ nào được coi là tuân thủ tốt trong điêu trị [4]. Tại Việt Nam, Bùi Thị Nhi nghiên cứu tại 1 xã ở tỉnh Long An năm 2015 cho thấy, chỉ có $48,3 \%$ BN tuân thủ dùng thuốc trong điều trị [5]. Nguyễn Thị Thơm, tỷ lệ tuân thủ điều trị chung ở BN THA ngoại trú tại BVĐK tỉnh Quảng Ninh là $79,6 \%$ [6]. Thạch Thị Mỹ, nghiên cứu BN THA tại BVĐK khu vực Cầu Ngang, Trà Vinh, tỷ lệ tuân thủ chế độ điều trị gồm: dùng thuốc $(3,4 \%)$, ăn giảm măn $(34,7 \%)$, sử dụng rượu/bia $(66,0 \%)$ và không hút hoặc bỏ hút thuốc lá $(72,1 \%)$ [7].

Điêu tra thực trạng (trước can thiệp) BN THA đang được theo dõ̉i tại TYT phường Linh Xuân, quận Thủ Đức, TP. Hồ Chí Minh năm 2019 cho thẩy, tỷ lệ tuân thủ chế độ trong điều trị đạt thấp: uống thuốc (18,8\%); kiểm tra (đo) HA thường xuyên $(16,4 \%)$, tái khám định kỳ đúng hẹn $(29,7 \%) ;$ ăm giảm mặn $(45,9 \%)$... Tỷ lệ BN đạt HA mục tiêu rất thấp $(12,7 \%)$. Từ thực trạng này, đề tài đã triển khai thí điểm giải pháp "Quản lý, điều trị BN THA tại TYT" phường Linh Xuân, quận Thủ Đức nhằm nâng cao chất lượng quản lý, điều trị BN THA tại tuyến cơ sở đạt hiệu quả hơn. Mục tiêu nghiên cứu "Đánh giá hiệu quả can thiệp cải thiện tuân thủ điều trị, đạt huyết áp mục tiêu ở bềnh nhân tăng huyết áp tại trạm y tế phường Linh Xuân, quận Thủ Đức, thành phố Hồ Chí Minh (2019 - 2020)".

\section{II. ĐỐI TƯƠNG VÀ PHƯƠNG PHÁP NGHIÊN CỨU} 1. Đô̂i tượng, địa điểm, thời gian nghiên cứu

- BN THA. Tiêu chuẩn lựa chon: BN THA độ I II, đang điều trị ngoại trú tại các cơ sở y tế (công, tư') hoặc tự điều trị, tự nguyện tham gia nghiên cứu; có hộ khẩu thường trú và bảo hiểm y tế tại phường nghiên cứu.

- Hồ sơ, sổ sách, báo cáo về hoạt động quản lý, điều trị THA của TYT.

- Nghiên cứu tại TYT phường Linh Xuân, quận Thủ Đức, thành phố Hồ Chí Minh.

- Thời gian nghiên cứu can thiệp: Từ 01/2019 - 06/2020 (18 tháng).

\section{Phương pháp nghiên cứu}

- Thiết kế nghiên cứu: Mô tả cắt ngang, phân tích số liệu thứ cấp, can thiệp cộng đồng không có đối chứng.

- Cỡ mẫu và chọn mẫu: Chọn toàn bộ 292 BN THA đạt các tiểu chí lựa chọn đối tương nghiên cứu, đăng ký, cam kêt tham gia giải pháp "Quản lý, điều trị THA tại TYT" của phường Linh Xuân, quận Thủ Đức.

\section{- Các chỉ số nghiên cứu:}

- Tuân thủ chế độ điều trị: Dựa theo các khuyến nghị của Hướng dẫn chẩn đoán và điêuu trị THA của Bộ Y tế năm 2012, gồm: [8].

+ Tuân thủ uống thuốc: Uống thuốc theo đúng chỉ định của bác sĩ;

+ Tuân thủ chế độ ăn: Giảm ăn mặn $(<6$ gam muối hay 1 thìa cà phê muối mối ngày); nhiều rau, củ, quả (trung bình ăn ít nhất 400 gram ( 5 đớn vị chuẩn) rau củ, trái cây trong một ngày); Giảm chất béo, mõ động vật.

+ Tuân thủ lối sống lạnh mạnh: Bỏ hoặc ngưng hoàn toàn hút thuốc lá/lào; hạn chế uống rượu/bia (số lượng ít hơn 3 cốc chuẩn/ngày (nam), ít hơn 2 cốc chuẩn/ngày (nữ) và tổng cộng ít hơn 14 cốc chuẩn/tuần (nam), ít hơn 9 cốc chuẩn/tuần (nữ). 1 cốc chuẩn chứa $10 \mathrm{~g}$ ethanol tương đương với $330 \mathrm{ml}$ bia hoặc $120 \mathrm{ml}$ 
rượu vang, hoặc 30ml rượu mạnh);

+ Tuân thủ luyện tập thể dục: Tập thể dục, đi bộ hoặc vận động ở mức độ vừa phải, đều đặn khoảng $30-60$ phút mỗi ngày, mỗi tuần 5 ngày;

+ Tuân thủ tái khám định kỳ đúng lịch hẹn của bác sĩ mỗi tháng một lần;

+ Tuân thủ theo dõi, kiểm tra HA thường xuyên tại nhà: Đo HA 1-2 lần/ngày.

+ Tỷ lệ BN đạt "HA mục tiêu" (< 140/90mmHg)

Tính chỉ số hiệu quả (CSHQ) về đạt HA mục tiêu.

- Các hoạt động can thiệp: Đối với TYT, nhân viên TYT, nhân viên tổ dân phố của phường Linh Xuân: tập huấn, nâng cao năng lực chuyên môn trong việc đo $\mathrm{HA}$, chẩn đoán, điều trị THA; theo dõi, quản lý BN THA tại TYT và tại nhà và kỹ năng giáo dục, tư vấn cho $B N$ tuân thủ chế độ điều trị THA (sử dụng thuốc hạ áp, ăn, uống, dinh dưỡng, luyện tập thể dục, nghỉ ngơi hàng ngày hợp lý; thực hiện lối sống lành mạnh; theo dõi/đo HA hàng ngày tại nhà; tái khám định kỳ theo chỉ định của bác sĩ...). Đối với BN THA: được khám lâm sàng, đo $\mathrm{HA}$ trước can thiệp (phân loại THA); được kê đơn, cấp phát thuốc thuốc điều trị THA theo chế độ bảo hiểm y tế; định kỳ mỗi tháng tái khám tại TYT một lần để duy trì hoặc điều chỉnh đơn thuốc khi cần thiết; được lập sổ theo dõi HA cá nhân tại nhà; được giáo dục sức khỏe và tư vấn trực tiếp, gián tiếp về các biện pháp tuân thủ chế độ điều trị THA; hướng dẫn ghi chép các chỉ số theo dõi HA vào sổ "Theo dõi HA tại nhà"...

- Phương pháp và kỹ thuật thu thập số liệu:

+ Phỏng vấn trực tiếp $B N$ THA bằng bảng hỏi; đo $\mathrm{HA}$, chỉ số nhân trắc (BMI) của $B N$; phân tích số liệu thứ cấp sổ khám bệnh, sổ theo dõi HA tại nhà, bệnh án ngoại trú và hồ sơ, sổ sách quản lý, điều trị THA tại TYT Phường.

+ Đánh giá các chỉ số nghiên cứu tại các thời điểm: Trước can thiệp (T0); sau can thiệp 3 tháng (T3), 6 tháng (T6), 12 tháng (T12) và 18 tháng (T18).

- Chẩn đoán THA và sử dung thuốc điêu trị THA: Theo hướng dẫn của Bổ Y tế [8].

- Xử lý và phân tích số liệu: Các số liệu được nhập vào máy tính bằng phần mềm Excel veresion 2016, phân tích số liệu bằng phần mềm SPSS 20.0. Số liêu được trình bày dưới dang tần số và tỷ lệ \%. Sử dụng các Test thống kê McNemar test và giá trị $p$-value để biểu thị sự khác biệt giữa hai tỷ lệ trước và sau can thiệp ở các thời điểm cho từng biến số. Tính hiệu quả làm tăng tỷ lệ đạt HA mục tiêu sau can thiệp ở các thời điểm T3, T6, T12 và T18 bằng CSHQ.

\section{KẾT QUẢ NGHIÊN CứU}

\section{Hiệu quả cải thiện về tuân thủ điêuu trị của bệnh nhân tăng huyết áp}

Bảng 1. Tuân thủ uống thuốc, tái khám định kỳ và kiểm tra huyêt áp thường xuyên trước và sau can thiệp 3, 6, 12 và 18 tháng

\begin{tabular}{|c|c|c|c|c|c|}
\hline \multirow[b]{2}{*}{ Chế độ } & \multicolumn{5}{|c|}{ Tuân thủ các chế đô tai các thời điểm } \\
\hline & $\begin{array}{l}\text { T0 (0) } \\
(n=292)\end{array}$ & $\begin{array}{c}\text { T3 (1) } \\
(n=292)\end{array}$ & $\begin{array}{c}\text { T6 (2) } \\
(\mathrm{n}=292)\end{array}$ & $\begin{array}{l}\text { T12 (3) } \\
(\mathrm{n}=292)\end{array}$ & $\begin{array}{l}\mathbf{T 1 8}(4) \\
(\mathrm{n}=292)\end{array}$ \\
\hline Uống thuốc & $55(18,8)$ & $203(69,5)$ & $250(85,6)$ & $260(89,0)$ & $288(98,6)$ \\
\hline (McNemar test, $\mathrm{p}$-value) & \multicolumn{5}{|c|}{$\mathrm{p}_{(0-1)}<0,001 ; \quad \mathrm{p}_{(0-2)}<0,001 ; \quad \mathrm{p}_{(0-3)}<0,001 ; \quad \mathrm{P}_{(0-4)}<0,001$} \\
\hline Kiểm tra HA & $48(16,4)$ & $154(52,7)$ & $214(73,3)$ & $252(86,3)$ & $281(96,2)$ \\
\hline (McNemar test, p-value) & \multirow{2}{*}{\multicolumn{5}{|c|}{ 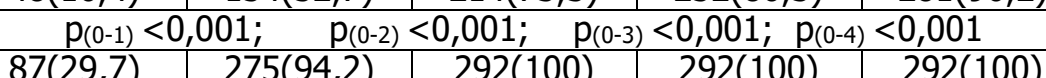 }} \\
\hline Tái khám & & & & & \\
\hline (McNemar test, p-valu) & \multicolumn{5}{|c|}{$\mathrm{p}_{(0-1)}<0,001 ; \quad \mathrm{P}_{(0-2)}<0,001 ; \quad \mathrm{P}_{(0-3)}<0,001 ; \quad \mathrm{P}_{(0-4)}<0,001$} \\
\hline
\end{tabular}

Tỷ lệ BN tuân thủ uống thuốc hạ HA, kiếm tra HA thường xuyên và tái khám định kỳ đúng lịch hẹn tại thời điểm T3, T6, T12 và T18 đều tăng rõ rệt so với thời điểm T0. Sự khác biệt về tỳ lệ tuân thủ ở các thời điểm sau can thiệp so với T0 là có ý nghĩa thống kê $(p<0,01)$.

Bảng 2. Tỷ lệ bệnh nhân tăng huyêt áp tuân thư chê độ ăn, uông, luyện tập thể dục trước và sau can thiệp 3, 6, 12 và 18 tháng

\begin{tabular}{|c|c|c|c|c|c|}
\hline \multirow[b]{2}{*}{ Chế độ } & \multicolumn{5}{|c|}{ Tuân thủ các chế độ tại các thời điểm } \\
\hline & $\begin{array}{c}\text { T0 (0) } \\
(n=292)\end{array}$ & $\begin{array}{c}\text { T3 (1) } \\
(n=292)\end{array}$ & $\begin{array}{c}\text { T6 (2) } \\
(n=292)\end{array}$ & $\begin{array}{l}\text { T12 (3) } \\
(n=292)\end{array}$ & $\begin{array}{l}\text { T18 (4) } \\
(n=292)\end{array}$ \\
\hline Ån giảm mặn & $134(45,9)$ & $90(69,2)$ & $222(76,0)$ & $245(83,9)$ & $256(87,7)$ \\
\hline (McNemar test, p-value) & \multicolumn{5}{|c|}{$\mathrm{p}_{(0-1)}<0,001 ; \quad \mathrm{p}_{(0-2)}<0,001 ; \quad \mathrm{p}_{(0-3)}<0,001 ; \quad \mathrm{p}_{(0-4)}<0,001$} \\
\hline Àn rau, củ, quả nhiều & $150(51,4)$ & $214(73,3)$ & $250(85,6)$ & $258(88,4)$ & $270(92,5)$ \\
\hline (McNemar test, p-valu) & \multicolumn{5}{|c|}{$\mathrm{P}_{(0-1)}<0,001 ; \quad \mathrm{P}_{(0-2)}<0,001 ; \quad \mathrm{P}_{(0-3)}<0,001 ; \quad \mathrm{P}_{(0-4)}<0,001$} \\
\hline Giảm chất béo, mõ̃ động vật & $154(52,7)$ & $211(72,3)$ & $248(84,9)$ & $269(92,1)$ & $268(91,8)$ \\
\hline
\end{tabular}




\begin{tabular}{|c|c|c|c|c|}
\hline (McNemar test, $\mathrm{p}$-value) & $\mathrm{P}(0-1)<0,001 ;$ & ,001; & $<0,001 ; \quad \mathrm{P}($ & $<0,001$ \\
\hline Hạn chế uống rượu/ bia & \begin{tabular}{|l|l|}
$206(70,5)$ & $219(75,0)$ \\
\end{tabular} & $236(80,8)$ & $247(84,5)$ & $254(87,0)$ \\
\hline (McNemar test, p-value) & \multicolumn{4}{|c|}{$\mathrm{p}_{(0-1)}<0,05 ; \quad \mathrm{P}_{(0-2)}<0,01 ; \quad \mathrm{P}_{(0-3)}<0,01 ; \quad \mathrm{P}_{(0-4)}<0,01$} \\
\hline Ngưng hút thuốc & \begin{tabular}{l|l}
$220(75,3)$ & $232(79,5)$ \\
\end{tabular} & $239(81,8)$ & $246(84,2)$ & $251(86,0)$ \\
\hline (McNemar test, p-value) & \multicolumn{4}{|c|}{$\mathrm{p}_{(0-1)}<0,05 ; \quad \mathrm{p}_{(0-2)}<0,01 ; \quad \mathrm{P}_{(0-3)}<0,01 ; \quad \mathrm{P}_{(0-4)}<0,01$} \\
\hline Tập thể dục thường xuyên & \begin{tabular}{l|l}
$142(48,6)$ & $228(78,1)$ \\
\end{tabular} & $249(85,3)$ & $260(89,0)$ & $268(91,8)$ \\
\hline (McNemar test, $\mathrm{p}$-value) & \multicolumn{4}{|c|}{$\mathrm{p}_{(0-1)}<0,001 ; \quad \mathrm{p}_{(0-2)}<0,001 ; \quad \mathrm{P}_{(0-3)}<0,001 ; \quad \mathrm{P}_{(0-4)}<0,001$} \\
\hline
\end{tabular}

Tỷ lệ BN tuân thủ chế độ ăn giảm mặn, nhiều rau/củ/quả, giảm chất béo, mõ̃ động vật, hạn chế uống rượu/bia, ngưng hút thuốc và tập thể dục thường xuyên các thời điểm T3, T6, T12 và T18 đều tăng rõ rệt so với thời điểm T0. Sự khác biệt về tỷ lệ tuân thủ các chế độ ở các thời điểm sau can thiệp so với T0 là có ý nghĩa thống kê $(p<0,05)$.

2. Hiệu quả cải thiện tỷ lệ bệnh nhân đạt huyết áp mục tiêu

Bảng 3. Tỷ lệ bệnh nhân đạt huyết áp mục tiêu ở các thời điểm trước và sau can thiệp

\begin{tabular}{|c|c|c|c|c|c|}
\hline Mức độ THA & $\begin{array}{c}\mathrm{TO}(\mathrm{n}=292) \\
(0)\end{array}$ & $\begin{array}{c}\text { T3(n=292) } \\
(1)\end{array}$ & $\begin{array}{c}\text { T6(n=292) } \\
(2)\end{array}$ & $\begin{array}{c}\operatorname{T12}(n=292) \\
(3)\end{array}$ & $\begin{array}{c}\operatorname{T18}(n=292) \\
(4)\end{array}$ \\
\hline Đạt HA mục tiêu & $37(12,7)$ & $97(33,2)$ & $152(52,0)$ & $226(77,4)$ & $276(94,5)$ \\
\hline CSHQ (\%) & \multirow{2}{*}{\multicolumn{5}{|c|}{$\begin{array}{cccc}(161,4 \%) ; & (309,4 \%) ; & (509,4 \%) ; & (644,1 \%) \\
\left(\mathrm{p}_{(0-1)<0,001) ;}\right. & \left(\mathrm{p}_{(0-2)<0,001) ;}\right. & \left(\mathrm{p}_{(0-3)<0,001) ;}\right. & \left(\mathrm{p}_{(0-4)}<0,001\right)\end{array}$}} \\
\hline (McNemar tes & & & & & \\
\hline & $186(63,7)$ & $137(46,9)$ & $95(32,5)$ & $40(13,7)$ & $11(3,8)$ \\
\hline $\begin{array}{c}\text { CSHQ (\%) } \\
\text { (McNemar test n-valu) }\end{array}$ & \multicolumn{5}{|c|}{$\begin{array}{cccc}(-26,4 \%) ; & (-49,0 \%) ; & (-78,5 \%) ; & (-94,0 \%) \\
\left(\mathrm{p}_{(0-1)}<0,001\right) ; & \left(\mathrm{p}_{(0-2)}<0,001\right) ; & \left(\mathrm{p}_{(0-3)}<0,001\right) ; & \left(\mathrm{p}_{(0-4)}<0,001\right)\end{array}$} \\
\hline & $69(23,6)$ & $58(19,9)$ & $45(15,5)$ & $26(8,9)$ & $9(3,1)$ \\
\hline $\begin{array}{c}\text { CSHQ }(\%) \\
\text { (McNemar test, } \mathrm{p} \text {-valu) }\end{array}$ & \multicolumn{5}{|c|}{$\begin{array}{cccc}(-15,7 \%) ; & (-34,3 \%) ; & (-62,3 \%) ; & (-86,7 \%) \\
\left(p_{(0-1)}<0,001\right) ; & \left(p_{(0-2)}<0,001\right) ; & \left(p_{(0-3)}<0,001\right) ; & \left(p_{(0-4)}<0,001\right)\end{array}$} \\
\hline THA độ 3 & $0(0,0)$ & $0(0,0)$ & $0(0,0)$ & $0(0,0)$ & $0(0,0)$ \\
\hline
\end{tabular}

- Sau can thiệp, tỷ lệ BN đạt HA mục tiêu tăng lên rõ rệt, T3 (33,2\%); T6 (52,0\%); T12 (77,4\%) và T18 $(94,5 \%)$ so với To $(12,7 \%)$ (CSHQ đạt từ 161,4 - 644,1\%; $\mathrm{p}<0,001)$.

- Hiệu quả làm giảm tỷ lệ THA độ 1, 2 ở thời điểm T3 (46,9\% và 19,9\%); T6 (32,5\% và 15,5\%); T12 $(12,7 \%$ và $8,9 \%) ; T 18(3,8 \%$ và $3,1 \%)$ so với T0 $(63,7 \%$ và $23,6 \%)$ ( 18 (sau 18 tháng can thiệp). CSHQ giảm tương ứng là - 15,7\%; - 34,7\%; - 62,3\% và - 86,7\% $(p<0,001)$.

Bảng 4. Mối liên quan giứa giới tính và đạt huyết áp muc tiêu tại thời điểm trước và sau can thiệp 3, 6, 12 và 18 tháng

\begin{tabular}{|c|c|c|c|c|c|}
\hline \multirow{2}{*}{ Giới tính } & \multicolumn{5}{|c|}{ Đạt HA mục tiêu tại các thời điếm } \\
\cline { 2 - 6 } & T0 $(\mathrm{n}=292)$ & T3 $(\mathrm{n}=292)$ & $\mathbf{T 6}(\mathrm{n}=292)$ & $\mathbf{T 1 2}(\mathrm{n}=292)$ & T18 $(\mathrm{n}=292)$ \\
\hline Nam $(\mathrm{n}=130)$ & $15(11,5)$ & $40(30,8)$ & $64(49,2)$ & $91(70,0)$ & $117(90,0)$ \\
\hline Nữ $(\mathrm{n}=162)$ & $22(13,6)$ & $57(35,2)$ & $88(54,3)$ & $135(83,3)$ & $159(98,1)$ \\
\hline Cộng $(\mathrm{n}=292)$ & $37(12,7)$ & $97(33,2)$ & $152(52,0)$ & $226(77,4)$ & $276(94,5)$ \\
\hline $\begin{array}{c}\text { McNemar test, } \\
\text { p-value } \text { (nam-nứ) }\end{array}$ & $>0,05$ & $<0,05$ & $<0,05$ & $<0,05$ & $<0,05$ \\
\hline
\end{tabular}

Tại các thời điểm T3, T6, T12 và T18 cho thấy tỷ lệ đạt HA mục tiêu $(\leq 140 / 90 \mathrm{mmHg}$ ) ở nhóm BN nữ cao hơn nhóm BN nam. Sự khác biệt giữa hai tỷ lệ của nam và nữ ở các thời điểm sau can thiệp là có ý nghĩa thống kê $(p<0,05)$.

Bảng 5. Môi liên quan giữa nhóm tuổi và đạt huyêt áp mục tiêu tại thời điểm trước và sau can thiệp 3, 6, 12 và 18 tháng

\begin{tabular}{|c|c|c|c|c|c|}
\hline \multirow{2}{*}{ Nhóm tuổi } & \multicolumn{5}{|c|}{ Đạt HA mục tiêu tại các thời điểm } \\
\hline & T0 $(n=292)$ & T3 $(n=292)$ & T6 $(n=292)$ & $\operatorname{T12}(n=292)$ & T18 $(n=292)$ \\
\hline$<50(n=33)(1)$ & $5(15,2)$ & $13(39,4)$ & $19(57,6)$ & $28(84,8)$ & $32(97,0)$ \\
\hline $50-59(n=118)(2)$ & $16(13,6)$ & $40(33,9)$ & $62(51,7)$ & $92(78,0)$ & $114(96,6)$ \\
\hline $60-69(n=141)(3)$ & $16(11,3)$ & $44(31,2)$ & $72(51,0)$ & $106(75,2)$ & $130(92,2)$ \\
\hline McNemar test, $p$-value $(1-2)$ & $>0,05$ & $<0,05$ & $<0,05$ & $<0,05$ & $<0,05$ \\
\hline McNemar test, $p$-value $(1-3)$ & $>0,05$ & $<0,05$ & $<0,05$ & $<0,05$ & $<0,05$ \\
\hline
\end{tabular}

Tại các thời điểm T3, T6, T12 và T18 cho thấy tỷ lệ BN đạt HA mục tiêu $(\leq 140 / 90 \mathrm{mmHg})$ ở nhóm $B N<50$ tuổi cao hơn 2 nhóm BN 50 - 59 tuổi và 60 - 69 tuổi. Sự khác biệt giữa hai tỷ lệ là có ý nghĩa thống kê $(p<0,05)$. 


\section{BÀN LUÂN \\ 1. Về hiêu quả cải thiên về tuân thủ điêu trị của bệnh nhân tăng huyết áp}

- Về tuân thủ dùng thuốc, kiểm tra HA và tái khám định kỳ: Trước can thiệp, tỷ lệ BN tuân thủ dùng thuốc (uống thuốc đúng giở, đúng liều, không quên thuốc), kiểm tra (đo $H A$ ) hàng ngày tại nhà thường xuyên và tái khám định kỳ đúng lịch hẹn của bác sĩ lần lượt là $18,8 \% ; 16,4 \%$ và $29,7 \%$. Tỷ lệ tuân thủ dùng thuốc và tái khám định kỳ thấp hơn và tuân thủ kiểm tra HA tại nhà cao hơn nghiên cứu của Nguyễn Thị Thơm và sộng sự $(79,6 \% ; 3,2 \%$ và $60,4 \%)[6]$. Tỷ lê tuân thủ dùng thuốc của chúng tôi cao hơn kết quả nghiên cứu của Thạch Thị Mỹ và cộng sự $(3,4 \%)$, tuy nhiên ngiên cứu này đã sử dụng thang đo của Morisky DE [3]. Sở dĩ tỷ lệ tuân thủ dùng thuốc, kiểm tra $\mathrm{HA}$, tái khám định trong kết quả nghiên cứu trước can thiệp của chúng tôi lại rất thấp, có thể $B N$ THA đầu vào của chúng tồi đang điều trị từ nhiều cơ sở y tế khác nhau (công, tư, tự điều trị) nên không được quản lý chặt chẽ, không ai nhắc nhở, tư vấn, kiểm tra, giám sát tuân thủ điều trị. Trong khi BN THA đâu vào của các nghiên cứu khác thì $100 \%$ là đang điêu trị ngoại trú tại các cơ sở y tế. Chính từ đặc điểm này, trong quá trình can thiêp quản lý và điều trị THA cho các BN tại TYT phường, chúng tôi đã sử dụng các nhân viên y tế tổ dân phố kiểm tra, nhắc nhở, theo dõi, giám sát các $\mathrm{BN}$ thực hiện và tuân thủ chế độ điêuu trị hàng ngày và thường xuyên, do đó sau can thiệp tại các thời điểm $T 3, T 6, T 12$ và $T 18$, các tỷ lệ này được cải thiện rõ rệt (tăng cao và khá ổn định) tương ứng lần lượt là: T3 $(69,5 \% ; 52,7 \% ; 94,2 \%)$, T6 (85,6\%; 73,3\%; 100\%); T12 (89,0\%; 86,3\%; $100 \%) ;$ T18 (98,6\%; 96,2\%; 100\%). Sự khác biệt về tỷ lệ tuân thủ ở cả bốn thời điểm sau can thiệp so với T0 là có ý nghĩa thống kê $(p<0,01)$.

- Về tuân thủ chế độ ăn, uống, luyện tập thể dục: Trong điều trị THA, để kiểm soát được $\mathrm{HA}$ hay để đạt được $\mathrm{HA}$ mục tiêu ổn định và ngăn chặn được các biến chứng nguy hiểm thì các biện pháp thay đổi lối sống, chế độ dinh dưỡng, luyện tập thể lực có vai trò rất quan trọng góp phần làm giảm liều và lượng thuốc sử dung. Trong thay đổi lối sống, việc đâu tiên là tuân thủ chế độ ăn, uống đối với BN THA, đó là chế độ ăn giảm mặn, giảm chất béo, mõ động vật (mõ đông vật, phủ tạng động vật, thịt nguội chế biến sẵn...). Kết quả nghiển cứu cho thấy, trước can thiệp có $45,9 \%$ ăn giảm mặn, cao hơn nghiên cứu của Thach Thi Mỹ $(34,7 \%)$ [7], thấp hơn nghiên cứu của Nguyễn Thị Thơm $(54,8 \%)$ [6].
Ăn giảm chất béo, mõ động vật là $52,7 \%$, thấp hơn nghiên cứu của Nguyễn Thị Thơm $(64,8 \%)$ [6], Thạch Thị Mỹ $(58,5 \%)$ [7]. Kết quả của chúng tồi cho thấy, trước can thiệp tỷ lệ $B N$ BN hạn chế uống rượu/bia, bỏ hoặc ngưng hút thuốc là $70,5 \%$ và $75,3 \%$. Hai chỉ số này cũng tương đồng với nghiên cứu của Thạch Thị Mỹ $(72,4 \%$ và $72,1 \%)[7]$, nhưng cao nghiên cứu của Nguyễn Thị Thơm (47,2\% và 54,8\%) [6]. Thực hiện ăn rau xanh/củ/quả nhiều, kết quả của chúng tôi trước can thiệp có $51,4 \%$ BN tuân thủ, thấp hơn nghiên cứu của Nguyễn Thị Thơm $(80,8 \%)[6]$. Thực hiện tập thể dục thường xuyên, trước can thiệp tỷ lệ BN tuân thủ trong nghiên cứu của chúng tôi là $48,6 \%$, cao hơn nghiên cứu của Nguyền Thị Thơm $(44,4 \%)$ [6]. Sau can thiệp, tỷ lệ BN tuân thủ các chế độ ăn uống, dinh dưỡng hợp lý, lối sống lành mạnh, do đó từ thời điểm T3 trở lên các chỉ số theo dõi đánh giá đã được cải thiện đáng kể theo chiều hướng tốt hơn lển. Cụ thể, tỷ lệ BN tuân thủ chễ đô ăn giảm mặn; nhiều rau/củ/quả; giảm chất béo, mõ̃ động vật; hạn chế uống rượu/bia; bỏ hoặc ngưng hút thuốc và tập thể dục thường xuyên, thời điểm T0 tương ứng là 14,9\%; $51,4 \%$ và $52,7 \%$. Các thời điểm $T 3, T 6, T 12$ và $T 18$, tỷ lệ này tăng tương ứng lần lượt là: T3 $(69,2 \%$; $73,3 \% ; 72,3 \% ; 70,5 \% ; 75,3 \%$ và $48,6 \%)$, T6 $(76,0 \% ; 85,6 \% ; 84,9 \% ; 80,8 \% ; 81,8 \%$ và $85,3 \%) ;$ T12 (83,9\%; 88,4\%; 92,1\%; 84,5\%; $84,2 \%$ và $89,0 \%) ;$ T18 $(87,7 \% ; 92,5 \% ; 91,8 \%$; $87,0 \% ; 86,0 \%$ và $91,8 \%)$. Sự khác biệt về tỷ lệ tuân thủ các chế độ ở cả bốn thời điểm so với TO là có ý nghĩa thống kê $(p<0,001 ; p<0,05 ; p<0,01)$.

2. Về hiêu quả cải thiên tỷ lề bênh nhân đat huyết áp mục tiêu. Sự thay đổi tỷ lê đat HA mục tiêu của các BN THA được quản lý và điều trị tại TYT trước và sau can thiệp: Trong nghiên cứu này chúng tôi can thiệp điều trị dùng thuốc theo hướng dẫn của Bộ Y tế (2012) [8], nhằm đạt mục đích là hạ chỉ số HA đang ở mức cao về HA muc tiêu chung cho các BN là THA độ 1,2 về mức HATT $<140 \mathrm{mmHg}$ và HATTr $<90$ $\mathrm{mmHg}$ [8]. Kết quả cho thấy thời gian điều trị càng dài thì tỷ lê BN đạt HAMT càng cao. Sau 3 tháng tỷ lê BN đạt HA mục tiêu là 33,2\% (CSHQ $=161,4 \%)$, sau 6 tháng tỷ lệ này tăng lên $52,0 \% \quad(\mathrm{CSHQ}=309,4 \%)$, sau 12 tháng lên $77,4 \%(\mathrm{CSHQ}=509,4 \%)$ và đến tháng thứ 18 , tỷ lệ BN đạt HA mục tiêu là 94,5\% (CSHQ=664,1\%).

\section{KẾT LUẬN}

Sau can thiệp, tỷ lệ BN tuân thủ chế độ điều trị như: uống thuốc, tái khám định kỳ, kiểm tra huyết áp thường xuyên, chễ độ ăn, uống, lối 
sống (giảm mặn, tăng rau/củ/quả, giảm chất béo, giảm rượu/bia, ngưng hút thuốc, tập thể dục thường xuyên) được cải thiện rõ rệt. Sự khác biêt về tỷ lệ tuân thủ các chế độ ở cả bốn thời điểm T3, T6, T12 và T18 so với T0 đều có ý nghĩa thống kê $(p<0,05)$.

- Tăng tỷ lệ đạt HA mục tiêu sau can thiệp 18 tháng (T18) lên $94,5 \%$ (nữ: $98,1 \%$ cao hơn nam: 90,0\%; nhóm BN <50 tuổi: 97,0\% cao hơn nhóm 50-59 tuổi: 96,6\% và nhóm 60-69 tuổi: 92,2\%).

\section{TÀI LIÊU THAM KHẢO}

1. Nguyễn Lân Việt (2016). Kết quả mới nhất điều tra tăng huyết áp toàn quốc năm 2015 - 2016, Hội nghị tăng huyết áp Việt Nam lần thứ 2 tại Hà Nội, ngày $14-15 / 5 / 2016$.

2. Phạm Mạnh Hùng và cs (2010). Tìm hiểu và kiểm soát tăng huyết áp, Hội Tim mạch học quốc gia Viêt Nam, Hà Nôi

3. Morisky DE et al (2008). Predictive Validity of $A$ Medication Adherence Measure in an Outpatient etting, J Clin Hypertens, 10(5): 348-354.

4. Saleem F., Hassali M A., Shafie A.A (2011). Association between Knowledge and Drug Adherence in Patients with Hypertension in Quetta, Pakistan. TJPR, 10(2): 125-132.

5. Bùi Thị Nhi, Trịnh Thị Hoàng Oanh (2016). Tỷ lệ tuân thủ điều trị tăng huyết áp tai xã Phước Lơi, huyện Bến Lức, tính Long An năm 2015, Tạp chí Y học TP. Hố Hồ Chí minh, 20(1):268-272.

6. Nguyễn Thị Thớm, Bùi Văn Cường, Nguyễn Hống Hạnh và cs (2018). Thực trạng tuân thủ điều trị tăng huyết áp của người bệnh điều trị ngoại trú tai bệnh viện đa khoa tỉnh Quảng Ninh năm 2017, Tạp chí Khoa học Điêuu dướng, 1(3): 35-42.

7. Thạch Thị Mỹ, Lê Thị Diểm Trinh, Nguyễn La Trí Dũng và CS (2019). Tỷ lệ tuân thủ điêu trị và một số yếu tố liên quan ở bệnh nhân tăng huyết áp người dân tộc Khmer tại BVĐK khu vực Cầu Ngang, tỉnh Trà Vinh, Tạp chí Y học TP. Hồ Chí Minh, 23(2): 224-228.

8. Bộ Y' tế (2012). Hướng dẫn chẩn đoán và điều trị tẳng huyết áp (Ban hành kèm theo Quyết định số 3192/QĐ-BYT ngày 31/8/2010 của Bộ Y tế).

\section{TÌNH TRANG DINH DƯỡNG Ở' TRẺ 6 THÁNG ĐẾN 5 TUỔI TẠI PHÒNG KHÁM DINH DƯỡNG BỆNH VIỆN NHI TRUNG ƯƠNG}

\section{Aphanhnee Souliyakane ${ }^{1}$, Nguyễn Thị Yến ${ }^{1}$, Nguyễn Thị Thuý Hồng1, Chu Thị Phương Mai ${ }^{1}$, Lề Hưu Thành ${ }^{2}$}

\section{TÓM TẮT}

Đặt vấn đê: Dinh dưỡng là yếu tố quan trọng trong quá trình phát triển thể chất và tinh thần ở trẻ nhỏ, đặc biệt trẻ dưới 5 tuổi. Mục tiêu: Mô tả tình trang dinh dưỡng ở trẻ từ 6 tháng đến 5 tuổi và một sổ yếu tố liên quan tại Phòng khám Dinh dưỡng Bệnh viện Nhi Trung ương. Đối tượng và phương pháp: Nghiên cứu mô tả cắt ngang 234 trẻ từ 6 tháng đến 5 tuổi đến khám tại Phòng khám Dinh dưỡng Bệnh viện Nhi Trung ương từ tháng 9/2020 đến tháng 6/2021. Trẻ được đánh giá tính trạng dinh dưỡng theo tiêu chuẩn của Tổ chức Y tế Thế giới (WHO) 2006. Kết quả: Tỷ lệ trẻ được bú sữa me trong vòng 1 giờ là $56,0 \%$. Phần lớn trẻ bú mẹ hoàn toàn dưới 6 tháng $(67,1 \%)$. Tỷ lệ trẻ bú mẹ kéo dài trên 18 tháng là $58,8 \%$. Phần lớn trẻ ăn bổ sung đúng thời điểm $(87,0 \%)$; thành phân bữa ăn bổ sung có đủ các nhóm thực phẩm chiếm $67,9 \%$. Đa số trẻ ăn bổ sung đủ số bữa $(77,8 \%)$ nhưng chỉ có $41,9 \%$ trẻ ăn đủ số lượng thức ăn mối bữa. Tỷ lệ suy dinh dưỡng (SDD) thể thấp còi, nhe cân và gây còm lần lượt là $25,6 \%, 22,7 \%$ và $18,4 \%$, thừa cân béo phì chiểm $6,8 \%$. Trẻ có cân

\section{${ }^{1}$ Trường Đại học Y Hà Nội}

²Bênh viện Nội tiết Trung ương

Chịu trách nhiệm chính: Aphanhnee Souliyakane

Email: aphanisouliyakavn@gmail.com

Ngày nhận bài: 2.8.2021

Ngày phản biện khoa học: 24.9.2021

Ngày duyệt bài: 4.10.2021 năng lúc sinh thâp < $2500 \mathrm{~g}$ có nguy cơ suy dinh dưỡng thể nhe cân cao hơn nhóm trẻ có cân nặng lúc sinh bình thướng. Kết luận: Tỷ lệ trẻ SDD ở cả ba thể còn cao, ngoài ra có 1 tỷ lệ không nhỏ trẻ thừa cân béo phì. Cân nặng lúc sinh thấp có liên quan đến tình trạng dinh dướng của trẻ. trẻ em.

Tư khóa: suy dinh dưỡng, tính trạng dinh dưỡng,

\section{SUMMARY}

NUTRITIONAL STATUS IN 6 MONTH TO 5 YEAR OLD CHILDREN AT THE NUTRITION CLINICS OF THE CHILDREN'S NATIONAL HOSPITAL

Background: Nutrition plays an important role in the growth and development of a child, especially under 5 years old. Objectives: This study aimed to assess the nutritional status and associating factors of children aged from 6 months to 5 years old who visited the Nutrition Clinics at the Children's National Hospital. Methods: In this cross-sectional study, the nutirtional history and anthropometrics of 234 children aged from 6 months to 5 years old who visited the Nutrition Clinics at the Children's National Hospital from 9/2020 to 6/2021 were taken and interpreted based on the World Health Organisation (WHO) 2006 growth reference data. Results: $56,0 \%$ of subjects were breast-fed within an hour of life. $67,0 \%$ were fed entirely on breast milk for the first 6 months and $58,8 \%$ for the first 18 months. Complementary feeding was introduced at 6 months of age in $87,0 \%$ and $67,9 \%$ were provided with all food groups. While 